\title{
Selective and Sensitive Detection of Silver(I) Ion Based on Tetracationic Complex and TGA/GSH Co-capped Quantum Dots as an Effective Fluorescent Sensing Platform
}

\author{
Xue-Wen LIU, ${ }^{\dagger}$ Jun-Shi ShU, Yang XIaO, Yang YANG, and Song-Bai Zhang ${ }^{\dagger}$ \\ College of Chemistry and Chemical Engineering, Hunan University of Arts and Science, ChangDe 415000, \\ P. R. China
}

\begin{abstract}
CdTe quantum dots capped with glutathione (GSH) and thioglycolic acid (TGA) were synthesized and the interaction between QDs and tetracationic Fe complex was investigated. Based on the specific interaction between $\mathrm{Ag}^{+}$and cytosine bases (C), we designed a label-free DNA sensor for the detection of $\mathrm{Ag}^{+}$in aqueous solution. Furthermore, tetracationic Fe complex with a higher positive charge is demonstrated to improve the sensitivity of the sensor. A detection limit of $3.3 \mathrm{nmol} \mathrm{dm}-3$ was obtained, which was lower than in previous reports. This sensor also exhibits promising potential for real sample analysis.
\end{abstract}

Keywords Silver(I), CdTe quantum dots, TGA-GSH, tetracationic complex, DNA

(Received June 15, 2016; Accepted November 4, 2016; Published March 10, 2017)

\section{Introduction}

Silver compounds have been used for many years in industries such as those related to electronics, photography, pharmaceuticals and mirrors. ${ }^{1,2}$ A large amount of silver compounds are released to the environmental from industrial wastes and emissions annually. Among them, silver(I) ions are considered to be one of the highly toxic environmental pollutants and have shown high toxicity to aquatic organisms. Therefore, it is highly desirable to develop sensitive methods for the detection of $\mathrm{Ag}^{+}$. Indeed, a number of traditional methods have been established to detect silver ions at trace quantity levels in aqueous media, such as atomic absorption spectroscopy, inductively coupled plasma-mass spectroscopy and ion-selective electrodes. ${ }^{3-9}$ In order to overcome the drawbacks of the time-consuming and labor-intensive process of adding many exogenous reagents, and the need for specialized expertise or expensive equipment for these methods, much effort has been made to develop new silver ion $\left(\mathrm{Ag}^{+}\right)$fluorescent chemosensors for improved sensitivity, selectivity, instrument implementation and ease of operation.

Recently, several novel approaches for sensitive and specific fluorescent detection of $\mathrm{Ag}^{+}$based on interactions of $\mathrm{Ag}^{+}$ions with nucleic acids have attracted particular attention. $\mathrm{Ag}^{+}$can selectively interact with cytosine bases $(\mathrm{C})$ to form strong and stable C- $\mathrm{Ag}^{+}-\mathrm{C}$ complexes. ${ }^{10-18}$ Based on this fact, nanomaterial has been introduced for silver(I) ion detection. For example, $\mathrm{Li}$ et al. reported a graphene-based fluorescent DNA sensor for silver(I) ions detection. ${ }^{19}$ A fluorescein (FAM) labeled C-rich single strand DNA (ssDNA) was applied in this study. In the

$\dagger$ To whom correspondence should be addressed.

E-mail: liuxuewen050@sina.com (X-W. L.); zsb0119@163.com (S-B. Z.) absence of $\mathrm{Ag}^{+}$, graphene oxide (GO) can selectively absorb and quench the fluorescence of ssDNA by the formation of stable GO-DNA complexes. In the presence of $\mathrm{Ag}^{+}$, ssDNA can readily form $\mathrm{C}-\mathrm{Ag}^{+}-\mathrm{C}$ complexes with a rigid hairpin structure, and their fluorescence is retained.

In addition, a label-free fluorescent DNA sensor for silver(I) ion detection has also been developed. Shi et al. reported a novel fluorescent DNA sensor based on luminescent semiconductor quantum dots (QD) and ruthenium(II) complex for silver(I) ion detection. ${ }^{20}$ In the absence of $\mathrm{Ag}^{+}$, the positively charged $\mathrm{Ru}$ complex can quench the fluorescence of the negatively charged water-soluble TGA-capped CdTe quantum dots via the photoinduced electron transfer process, then with the addition of ssDNA, the strong binding between the ssDNA and $\mathrm{Ru}$ complex induces the fluorescent QDs to be set free and then the fluorescence is recovered. In the presence of $\mathrm{Ag}^{+}, \mathrm{Ag}^{+}$ can chelate cytosine bases (C) of ssDNA to form $\mathrm{C}-\mathrm{Ag}^{+}-\mathrm{C}$ complexes, which will cause the binding affinity between the ssDNA and Ru complex to decrease, and the fluorescence can not be recovered. Furthermore, the method also provided excellent selectivity toward the detection of $\mathrm{Ag}^{+}$. However, the detection limit reaches as high as $100 \mathrm{nmol} \mathrm{dm}^{-3}$. This may be due to a higher concentration of metal complex as the fluorescence quencher of QDs. The higher concentration of metal complex would lead to a high concentration of ssDNA, and that will result in higher detection limit of $\mathrm{Ag}^{+}$due to the formation of $\mathrm{C}-\mathrm{Ag}^{+}-\mathrm{C}$ complexes.

In this paper, we sought to form $\mathrm{C}-\mathrm{Ag}^{+}-\mathrm{C}$ complexes while reducing the concentration of metal complex and ssDNA, because the lower concentration of metal complex also leads to the lower concentration ssDNA and $\mathrm{Ag}^{+}$, which helps to improve the sensitivity of the sensor. In order to reduce the concentration of the quencher, we chose a tetracationic Fe complex $\left(\left[\mathrm{Fe}_{2} \mathrm{~L}_{3}\right]^{4+}\right.$, $\mathrm{L}=4,4^{\prime}$-methylenebis $[N$-(2-pyridinylmethylene)benzenamine) 


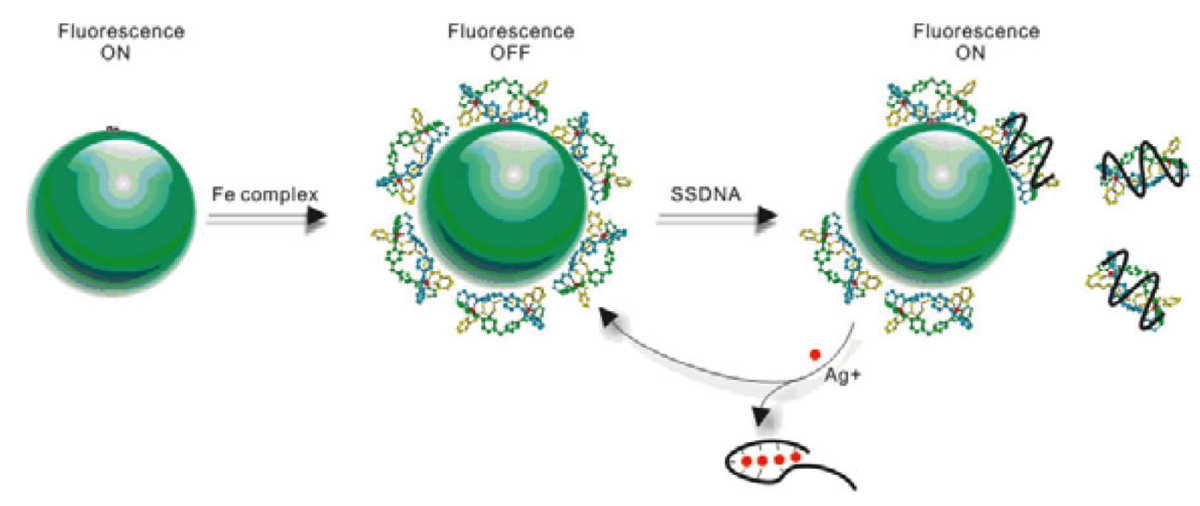

Scheme 1 The schematic illustration of the principle of $\mathrm{Ag}^{+}$detection using DNA-Fe-QDs system.

as fluorescence quencher of QDs (Scheme 1). It is obvious that a metal complex with higher positive charge would more efficiently quench the fluorescence of negative QDs since the electrostatic interaction between tetracationic Fe complex and negative QDs is stronger than that of ruthenium complexes reported before. ${ }^{20}$ Recently, it has been reported that CdTe QDs in the presence of both glutathione (GSH) and thioglycolic acid (TGA) (GSH-TGA-CdTe QDs) as stabilizers exhibited good biological compatibility and high fluorescence intensity. Compared to CdTe QDs single-capped with either GSH or TGA, the GSH-TGA-CdTe QDs has been proven to significantly improve fluorescence intensity and optical stability. In this work, we reported a new and simple method for selective detection of $\mathrm{Ag}^{+}$based on GSH-TGA-CdTe QDs, tetracationic $\mathrm{Fe}$ complex and C-rich single strand DNA (ss-DNA). The tetracationic $\mathrm{Fe}$ complex is demonstrated here to act as a more efficient quencher of QDs with the concentration of $0.62 \mu \mathrm{mol} \mathrm{dm}{ }^{-3}$. Furthermore, by combining tetracationic $\mathrm{Fe}$ complex, QDs and ssDNA, a simple, sensitive and selective method is provided for the detection of $\mathrm{Ag}^{+}$. And a lower detection limit is obtained.

\section{Experimental}

\section{Reagents}

The purified oligonucleotide was obtained from Sangon Biotechnology Co., Ltd. (Shanghai, PRC). The applied DNA sequence was given as: 5'-CTCTCTCCAACCTCTCTC-3' (ss-DNA). DNA stock solution was obtained by dissolving oligonucleotides in $10 \mathrm{mmol} \mathrm{dm}^{-3}$ HEPES-NaOH buffer (pH 7.4) and was stored at $4{ }^{\circ} \mathrm{C}$ before use. We used thioglycolic acid $\geq 98 \%$, glutathione $98 \%, \mathrm{CdCl}_{2} \cdot 2.5 \mathrm{H}_{2} \mathrm{O} 99.99 \%, \mathrm{~K}_{2} \mathrm{TeO}_{3}$ $99.5 \%$, and $\mathrm{NaBH}_{4} \geq 98 \%$. $\left[\mathrm{Fe}_{2} \mathrm{~L}_{3}\right]^{4+}\left(\mathrm{L}=4,4^{\prime}\right.$-methylenebis $[N-$ (2-pyridinylmethylene)benzenamine) was synthesized according to methods in the literature ${ }^{21}$ (Scheme S1, Supporting Information). All other chemicals were of analytical reagent grade and used as received. The water used was purified by Milli-Q (18 M $\Omega / \mathrm{cm})$.

\section{Measurements}

The UV-vis spectra were recorded on a UV-vis spectrophotometer (Shimadzu UV-2600, Japan). Fluorescence spectra were obtained by a Hitachi F-4500 spectrofluorometer (Japan). All the samples were excited at $365 \mathrm{~nm}$, and emission spectra were recorded in the region $450-700 \mathrm{~nm}$. The excitation and emission slit width were both $5 \mathrm{~nm}$ in the $\mathrm{Ag}^{+}$ detection. But in the experiment of optical properties of QDs, the excitation and emission slit width were both $2.5 \mathrm{~nm}$.

\section{Synthesis of GSH-TGA modified CdTe QDs}

CdTe QDs were synthesized according to methods in the literature with some modification..$^{22,23}$ Briefly, $46 \mathrm{mg}$ $\mathrm{CdCl}_{2} \cdot 2.5 \mathrm{H}_{2} \mathrm{O}$ was dissolved into $50 \mathrm{~mL}$ water. Then $9 \mu \mathrm{L}$ TGA and $6 \mathrm{mg}$ GSH were added and the $\mathrm{pH}$ of the mixture was adjusted to 9 with $1 \mathrm{~mol} \mathrm{dm}^{-3} \mathrm{NaOH}$ solution. After the mixture was deaerated by Ar bubbling for $30 \mathrm{~min}$, the $\mathrm{K}_{2} \mathrm{TeO}_{3}$ solution (10 $\mathrm{mg} \mathrm{K}_{2} \mathrm{TeO}_{3}$ in $50 \mathrm{~mL}$ water) was added to the $\mathrm{Cd}$ precursor solution, and the mixture was reacted for another 5 min under stirring. Then $40 \mathrm{mg} \mathrm{NaBH} 4$ was added, and the reaction mixture was refluxed under argon for additional time. The resulting QDs were denoted as GSH-TGA-CdTe.

\section{Experimental method}

For the quenching behavior of Fe complex on the fluorescence of QDs, $51 \mathrm{nmol} \mathrm{dm}^{-3}$ GSH-TGA-CdTe QDs and various amounts of $\left[\mathrm{Fe}_{2} \mathrm{~L}_{3}\right]^{4+}$ were incubated in $10 \mathrm{mmol} \mathrm{dm}^{-3}$ HEPES-NaOH buffer ( $\mathrm{pH}$ 7.4) at room temperature for $5 \mathrm{~min}$ respectively before fluorescence measurement.

For the detection of $\mathrm{Ag}^{+}, \mathrm{C}$-ssDNA was incubated with different concentrations of $\mathrm{Ag}^{+}$for $30 \mathrm{~min}$, then $\left[\mathrm{Fe}_{2} \mathrm{~L}_{3}\right]^{4+}$ was added to allow it to bind to DNA for $5 \mathrm{~min}$. Next, GSH-TGACdTe QDs was mixed with this solution and allowed to stand at room temperature for $5 \mathrm{~min}$ before fluorescence measurement. The final concentrations were $0.4 \mu \mathrm{mol} \mathrm{dm}^{-3}$ for ssDNA, $0.62 \mu \mathrm{mol} \mathrm{dm} \mathrm{dm}^{-3}$ for $\left[\mathrm{Fe}_{2} \mathrm{~L}_{3}\right]^{4+}$ and $51 \mathrm{nmol} \mathrm{dm}{ }^{-3}$ for QDs.

\section{Results and Discussion}

\section{Optical properties of GSH-TGA-CdTe QDs}

The UV-vis absorption and fluorescence spectra of CdTe QDs at room temperature are usually used to determine the sizedependent optical properties of CdTe QDs. Figure 1 shows the UV-vis absorption and fluorescence spectra of GSH-TGA-CdTe at different reflux times. As reported in the literature, with the prolonging of reflux time, an obvious red shift was observed for the absorption and fluorescence spectra of GSH-TGA-CdTe. This is attributed to the increasing size of QDs. After refluxing for $1.5 \mathrm{~h}$, GSH-TGA-CdTe exhibited the strongest emission intensity at $538 \mathrm{~nm}$. When the reflux time is prolonged, QDs emit yellow light. The particle size and concentration of QDs were calculated to be $2.29 \mathrm{~nm}$ and $10829.94 \mathrm{nmol} \mathrm{dm}^{-3}$, respectively, according to the following equation: ${ }^{24}$ 

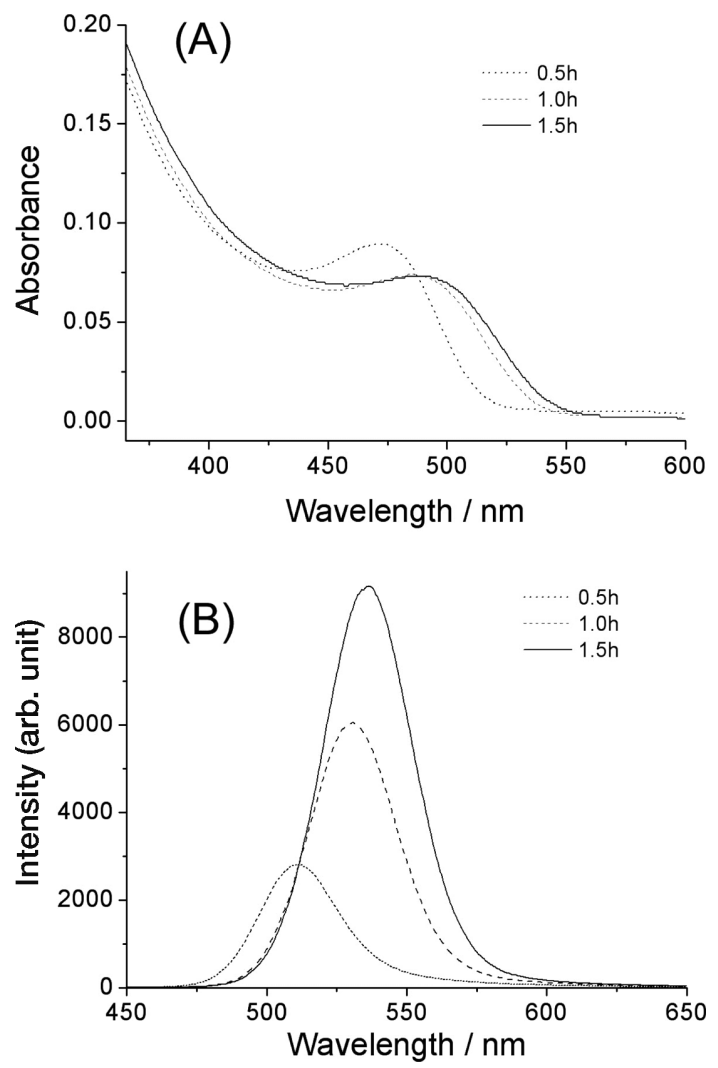

Fig. 1 UV-vis absorption (A) and fluorescence (B) spectra of GSHTGA-CdTe at different reflux time, $0.5 \mathrm{~h}$ (dot), $1.0 \mathrm{~h}$ (dash), $1.5 \mathrm{~h}$ (solid).

$$
\begin{aligned}
& D=\left(9.8127 \times 10^{-7}\right) \lambda^{3}-\left(1.7147 \times 10^{-3}\right) \lambda^{2}+ \\
& 1.0064 \lambda-194.84 \\
& C\left(\mathrm{~mol} \mathrm{~L}^{-1}\right)=A /\left[10043\left(D^{2.12}\right) l\right]
\end{aligned}
$$

in which, $D(\mathrm{~nm})$ is the diameter of a given $\mathrm{QD}, \lambda$ is the wavelength of the first excitonic absorption peak of UV-vis absorption spectra, $C$ is the concentration of QDs, and $A$ is the absorbance of the first excitonic absorption peak.

\section{Determination of DNA-Fe-QDs system}

It has been reported metal complexes can quench the fluorescence of QDs. In order to determine the quenching behavior of $\left[\mathrm{Fe}_{2} \mathrm{~L}_{3}\right]^{4+}$ on the fluorescence of QDs, the emission titration experiment was measured by adding different concentrations of Fe complex in $10 \mathrm{mmol} \mathrm{dm}^{-3}$ HEPES-NaOH buffer ( $\mathrm{pH}$ 7.4). The fluorescence intensity decreased with increasing concentration of Fe complex (Fig. 2A). When the concentration reached $0.62 \mu \mathrm{mol} \mathrm{dm}^{-3}$, the fluorescence intensity of QDs $\left(51 \mathrm{nmol} \mathrm{dm}^{-3}\right)$ decreased to about $1 \%$. In this paper, $\left[\mathrm{Fe}_{2} \mathrm{~L}_{3}\right]^{4+}$ is used as a quencher and the final concentrations were kept to $0.62 \mu \mathrm{mol} \mathrm{dm}{ }^{-3}$, while the final concentration of GSH-TGA-CdTe was $51 \mathrm{nmol} \mathrm{dm}^{-3}$. Figure $2 \mathrm{~B}$ shows the value of $I_{0} / I$ plotted against the concentration of Fe complex, where $I_{0}$ and $I$ are the fluorescence intensity of GSH-TGA-CdTe without and with Fe complex. The linear range is from 0.232 to $0.542 \mu \mathrm{mol} \mathrm{dm}{ }^{-3}$. The UV-vis spectra of GSH-TGA-CdTe (Fig. S1, Supporting Information) in the presence of $\left[\mathrm{Fe}_{2} \mathrm{~L}_{3}\right]^{4+}$ showed the increase in the absorbance of QDs solution. Compared to $\mathrm{Ru}$ complex reported before, tetracationic $\mathrm{Fe}$ complex exhibited a higher quenching efficiency, which
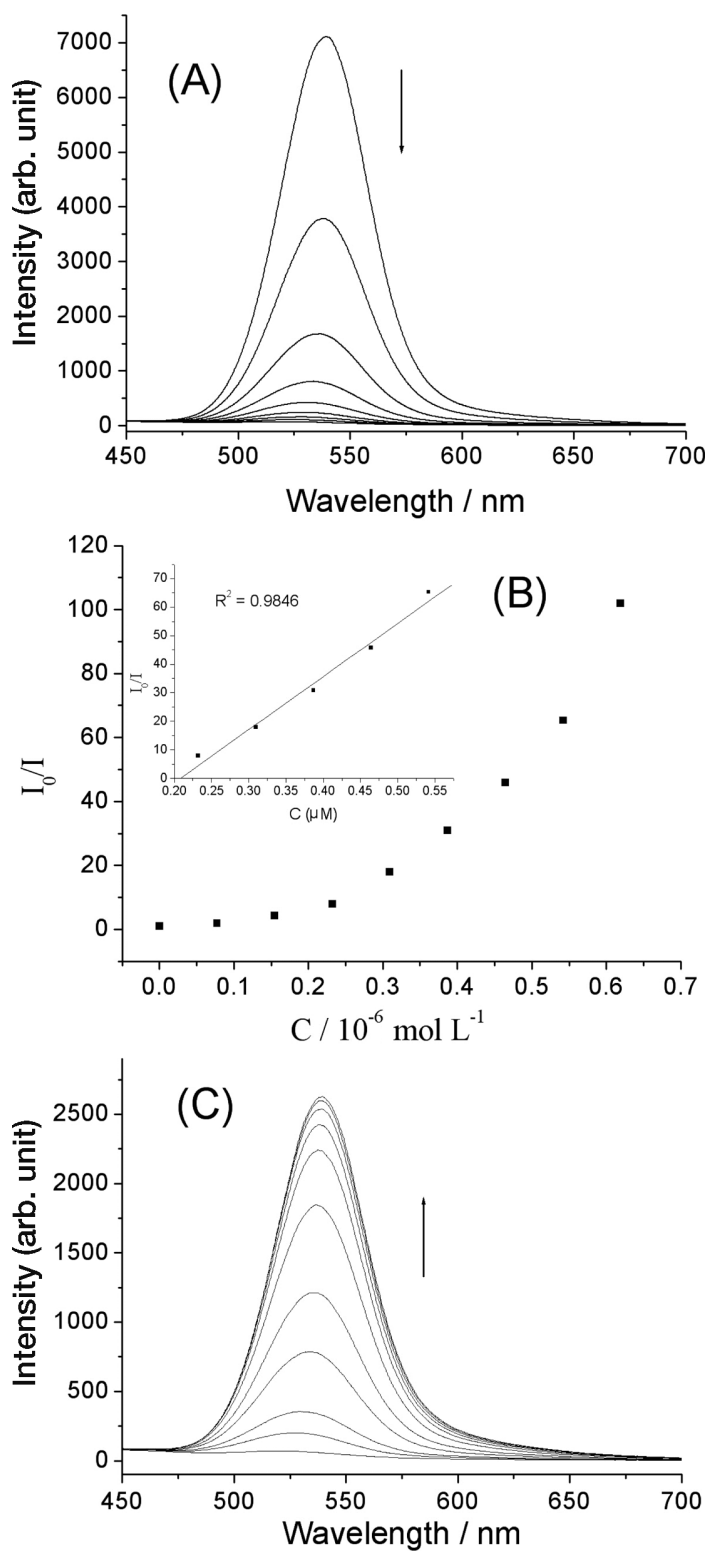

Fig. 2 (A) Fluorescence spectra of $51 \mathrm{nmol} \mathrm{dm}^{-3}$ QDs at different concentrations of $\mathrm{Fe}$ complex in HEPES-NaOH buffer, with concentrations of $0,0.078,0.155,0.232,0.310,0.387,0.464,0.542$, $0.620 \mu \mathrm{mol} \mathrm{dm}{ }^{-3}$. (B) Plots of the fluorescence intensity against the concentration of $\mathrm{Fe}$ complex. Inset: linear relationship between the fluorescence intensity and the concentration of $\mathrm{Fe}$ complex $\left(0.232-0.542 \mu \mathrm{mol} \mathrm{dm}^{-3}\right)$. (C) Fluorescence spectra of $51 \mathrm{nmol} \mathrm{dm}^{-3}$ QDs and $0.62 \mu \mathrm{mol} \mathrm{dm}^{-3} \mathrm{Fe}$ complex in the presence of different concentrations of ss-DNA. Excitation: $365 \mathrm{~nm}$.

indicated that cationic metal complex with higher positive charge is more beneficial for the fluorescence quenching of QDs since the quenching usually occurs by electronic interactions. In general, the high quenching efficiency could lead to a high signal-to-background ratio and good sensitivity target detection. The fluorescence intensity of the Fe-QDs system increased when the C-rich single strand DNA (C-ssDNA) was added into the solution, because it could remove the Fe complex via the strong electronic interaction between them. Figure $2 \mathrm{C}$ shows the changes of fluorescence intensity for the Fe-QDs system with increasing DNA concentration. When the concentration of DNA reached $0.4 \mu \mathrm{mol} \mathrm{dm}{ }^{-3}, 40 \%$ of fluorescence intensity of 

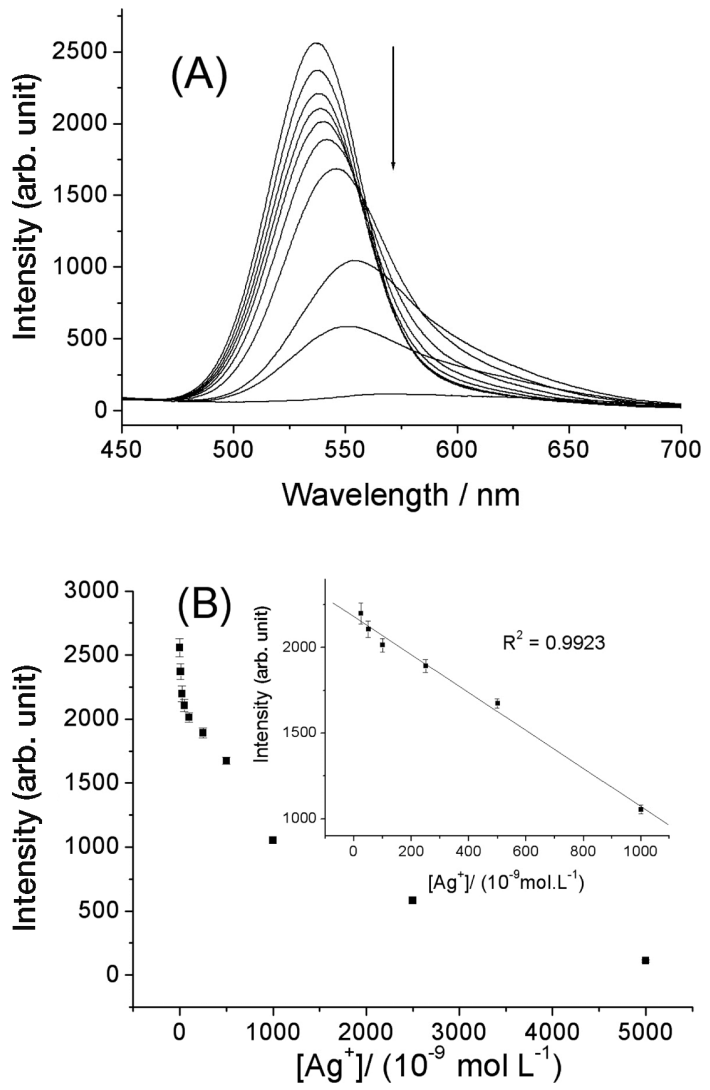

Fig. 3 (A) Fluorescence spectra of Fe-QDs in the presence of $0.4 \mu \mathrm{mol} \mathrm{dm}{ }^{-3}$ at different concentrations of $\mathrm{Ag}^{+}$with concentrations of $0,10,25,50,100,250,500,1000,2500,5000 \mathrm{~mol} \mathrm{dm}^{-3}$. (B) Plots of the fluorescence intensity against the concentration of $\mathrm{Ag}^{+}$. Inset: linear relationship between the fluorescence intensity and the concentration of $\mathrm{Ag}^{+}\left(25-1000 \mathrm{nmol} \mathrm{dm}{ }^{-3}\right)$; excitation: $365 \mathrm{~nm}$.

QDs was recovered. Although the fluorescence recovery efficiency is lower than that of the ruthenium complex reported before, the DNA-Fe-QDs system still exhibits strong emission intensity and could be applied for the detection of $\mathrm{Ag}^{+}$. Furthermore, the Fe complex has no fluorescence in the absence or presence of DNA, which has no influence on the detection of $\mathrm{Ag}^{+}$.

\section{Sensitivity of the DNA-Fe-QDs system}

To evaluate the sensitivity of the DNA-Fe-QDs system, the assay was tested on different concentrations of $\mathrm{Ag}^{+}$in the range of $0-5000 \mathrm{nmol} \mathrm{dm}^{-3}$. Figure 3 shows the fluorescence intensity of the DNA-Fe-QDs system in the presence of different $\mathrm{Ag}^{+}$concentrations in HEPES-NaOH buffer. Figure 3 inset shows the fluorescence intensity plotted against the $\mathrm{Ag}^{+}$ concentration. The fluorescence intensity of the DNA-Fe-QDs system decreased as the concentration of $\mathrm{Ag}^{+}$ions increased. The fluorescence intensity did not further decrease when the $\mathrm{Ag}^{+}$concentration was higher than $5 \mu \mathrm{mol} \mathrm{dm}{ }^{-3}$. Obvious red shift of the fluorescence spectra was also observed. The UV-vis spectra of GSH-TGA-CdTe (Fig. S2, Supporting Information) in the presence of $\mathrm{Ag}^{+}$showed a slight increment in the absorbance of the QDs solution and red shift of the absorption onsets. Han et al. ${ }^{25}$ reported that the red shift of CdTe QDs in the presence of $\mathrm{Ag}^{+}$is probably attributed to the creation of more radiative centers or more new defects by the complex of $\mathrm{Ag}^{+}$and TGA or GSH formed on the surface of CdTe QDs, not due to the aggregation induced by $\mathrm{Ag}(\mathrm{I})$ ions. From the

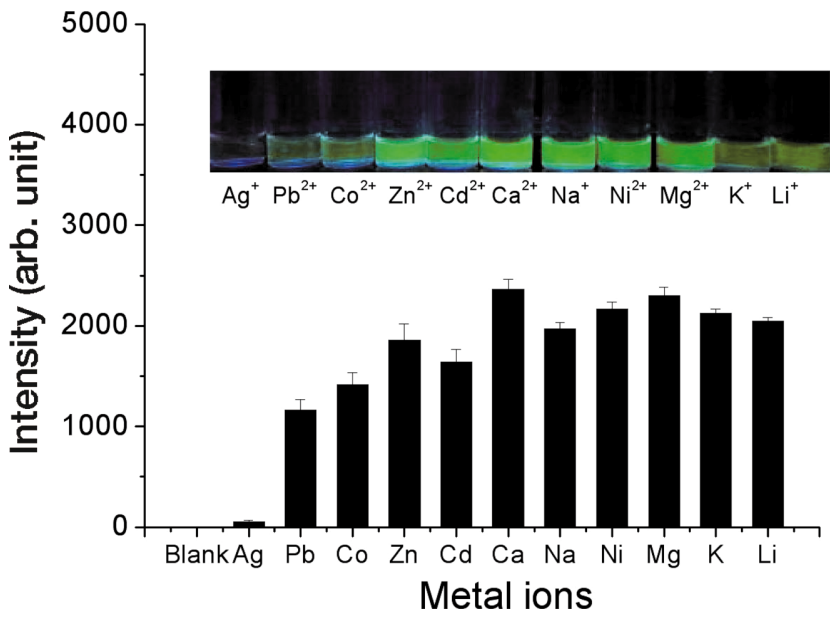

Fig. 4 Fluorescence spectra of DNA-Fe-QDs system with various metal ions $\left(20 \mu \mathrm{mol} \mathrm{dm}{ }^{-3}\right),\left[\mathrm{Ag}^{+}\right]=5 \mu \mathrm{mol} \mathrm{dm}{ }^{-3}$. The fluorescence intensities were recorded at $540 \mathrm{~nm}$. Exciation: $365 \mathrm{~nm}$. Inset: the photographic images of DNA-Fe-QDs system in the presence of various meal ions under a 365-nm UV lamp.

experiment results shown in Fig. 3B, a linear relationship was observed in the $\mathrm{Ag}^{+}$concentration range of $10 \mathrm{nmol} \mathrm{dm}^{-3}$ to $1 \mu \mathrm{mol} \mathrm{dm}{ }^{-3}$. The detection limit is $3.3 \mathrm{nmol} \mathrm{dm}^{-3}(S / N=3)$ $\left(R^{2}=0.9904\right)$. However, the nonlinear behavior was also observed at higher concentrations, a possible explanation for this phenomenon is that an excess amount of $\mathrm{Ag}^{+}$not only coordinated with cytosine bases (C) of ssDNA to form $\mathrm{C}-\mathrm{Ag}^{+}-\mathrm{C}$ complexes, but also bound to the surface of QDs (Figs. S2 and S3, Supporting Information).

\section{Selectivity of the DNA-Fe-QDs system}

To study the DNA-Fe-QDs system as a highly selective sensor for $\mathrm{Ag}^{+}$, selective experiments were performed by testing the response of the assay to other metal ions, including $\mathrm{Pb}^{2+}, \mathrm{Co}^{2+}$, $\mathrm{Zn}^{2+}, \mathrm{Cd}^{2+}, \mathrm{Ca}^{2+}, \mathrm{Na}^{+}, \mathrm{Ni}^{2+}, \mathrm{Mg}^{2+}, \mathrm{K}^{+}$, and $\mathrm{Li}^{+}$at a concentration $\left(20 \mu \mathrm{mol} \mathrm{dm}^{-3}\right)$ that was greater than that of the $\mathrm{Ag}^{+}$ions $\left(5 \mu \mathrm{mol} \mathrm{dm}{ }^{-3}\right)$. As shown in Fig. 4, the fluorescence of the DNA-Fe-QDs system was strongly quenched with the addition of $5 \mu \mathrm{mol} \mathrm{dm}{ }^{-3} \mathrm{Ag}^{+}$ion. However, there was very little decrease of the fluorescence intensity in the presence of other ions. The results indicated that the DNA-Fe-QDs system exhibited a reliable and highly selective sensor for $\mathrm{Ag}^{+}$. The specific detection for $\mathrm{Ag}^{+}$may be attributed mainly to its ability to chelate cytosine bases (C), which results in the formation of stable $\mathrm{C}-\mathrm{Ag}^{+} \mathrm{C}$ complexes. Figure 4 also shows that the detection selectivity could be visualized by the naked eye.

\section{Detection in river water}

The DNA-Fe-QDs system was applied for the determination of $\mathrm{Ag}^{+}$in real samples by using fresh river water. River water samples were obtained from the Yuan River of ChangDe, Hunan Province, China. The responses of the DNA-Fe-QDs system to blank river water (curve a) and river water spiked with $100 \mathrm{nmol}$ $\mathrm{dm}^{-3} \mathrm{Ag}^{+}$(curve b) are shown in Fig. 5. Due to the interference existing in river water, an obvious decrease in the fluorescence intensity of the DNA-Fe-QDs system was observed. However, the sensor can still distinguish the fresh river water and that spiked with $100 \mathrm{nmol} \mathrm{dm}^{-3} \mathrm{Ag}^{+}$. This result can satisfy the sensitivity requirement of $\mathrm{Ag}^{+}$detection in drinking water $\left(460 \mathrm{nmol} \mathrm{dm}^{-3}\right)$, as defined by the U.S. Environmental Protection Agency (EPA). 


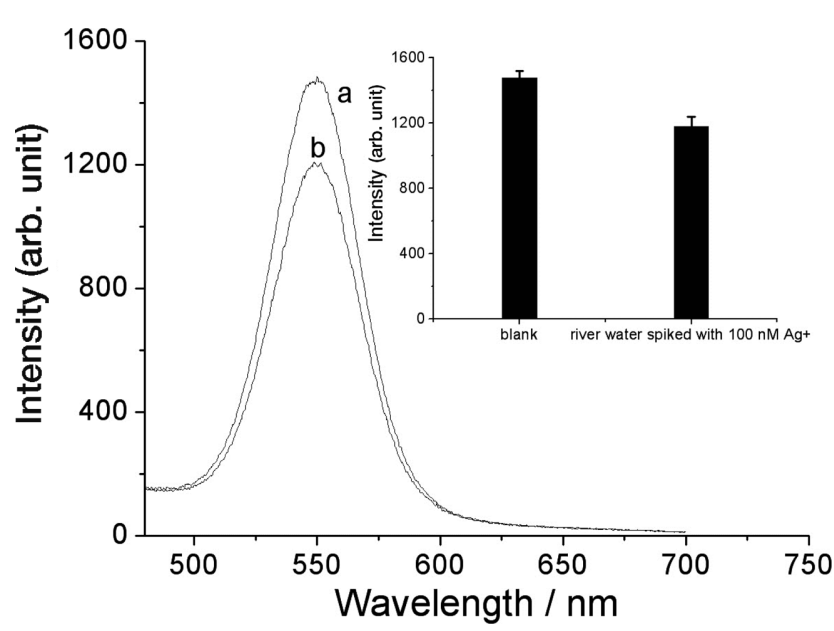

Fig. 5 Fluorescence spectra of DNA-Fe-QDs system in river water in the absence (a) and in the presence (b) of $100 \mathrm{nmol} \mathrm{dm}{ }^{-3} \mathrm{Ag}^{+}$. The fluorescence intensities were recorded at $548 \mathrm{~nm}$. Exciation: $365 \mathrm{~nm}$. Inset: the corresponding histograms with error bars.

\section{Conclusion}

In summary, we presented a highly sensitive and selective $\mathrm{Ag}^{+}$ ion determination method at room temperature using cytosine$\mathrm{Ag}^{+}$-cytosine coordination chemistry and fluorescence quenching of GSH-TGA-CdTe QDs by tetracationic complex. This method displayed excellent selectivity, high sensitivity, and lower detection limit toward $\mathrm{Ag}^{+}$than reported in earlier literature. A detection limit of $3.3 \mathrm{nmol} \mathrm{dm}{ }^{-3}$ was achieved.

\section{Acknowledgements}

We are grateful to support from the Natural Science Foundation of Hunan Province (14JJ7073), the Science Foundation of Hunan Province Education Department (16A145), the experiment project of the Undergraduate Innovative Training Center in Hunan Province (Materials Science and Engineering) (15YCZD02) and the Construct Program of the Key Discipline in Hunan Province (Applied Chemistry).

\section{Supporting Information}

Synthetic routes of $\left[\mathrm{Fe}_{2} \mathrm{~L}_{3}\right]^{4+}$; UV-vis absorption of GSH-TGACdTe before and after adding $\mathrm{Fe}$ complex or $\mathrm{Ag}^{+}$; fluorescence spectra of GSH-TGA-CdTe before and after adding $\mathrm{Ag}^{+}$. This material is available free of charge on the web of at http://www. jsac.or.jp/analsci/.

\section{References}

1. H. T. Ratte, Environ. Toxicol. Chem., 1999, 18, 89.

2. J. L. Barriada, A. D. Tappin, E. H. Evans, and E. P. Achterberg, Trends Anal. Chem., 2007, 26, 809.

3. M. Krachler, C. Mohl, H. Emons, and W. Shotyk, Spectrochim. Acta, Part B, 2002, 57, 1277.

4. K. Wygladacz, A. Radu, C. Xu, Y. Qin, and E. Bakker, Anal. Chem., 2005, 77, 4706.

5. X. Zhang, Z. Han, Z. Fang, G. Shen, and R. Yu, Anal. Chim. Acta, 2006, 562, 210.

6. G. Chakrapani, P. L. Mahanta, D. S. R. Murty, and B. Gomathy, Talanta, 2001, 53, 1139.

7. R. Freeman, T. Finder, and I. Willner, Angew. Chem., Int. Ed., 2009, 48, 7818.

8. Q. Pu, Q. Sun, Z. Hu, and Z. Su, Analyst, 1998, 123, 239.

9. S. Dadfarnia, A. M. Haji-Shabani, and M. Gohari, Talanta, 2004, 64, 682.

10. P. Jitaru, K. Tirez, and N. D. At. Brucker, Spectroscopy, 2003, 24, 1.

11. R. Yang, W. Chan, A. W. M. Lee, P. Xia, H. Zhang, and K. Li, J. Am. Chem. Soc., 2003, 125, 2884.

12. A. Ono, S. Cao, H. Togashi, M. Tashiro, T. Fujimoto, T. Machinami, S. Oda, Y. Miyake, I. Okamoto, and Y. Tanaka, Chem. Commun., 2008, 4825.

13. G. H. C lever, C. Kaul, T. Carell, Angew. Chem., Int. Ed., 2007, 46, 6226.

14. N. Dattagupta and D. M. Crothers, Nucleic Acids Res., 1981, 9, 2971.

15. S. Shukla and M. Sastry, Nanoscale, 2009, 1, 122.

16. T. Li, L. Shi, E. Wang, and S. Dong, Chem.-Eur. J., 2009, $15,3347$.

17. Y. Lin and W.-L. Tseng, Chem. Commun., 2009, 6619.

18. Y. Wen, F. Xing, S. He, S. Song, L. Wang, Y. Long, D. Li, and C. Fan, Chem. Commun., 2010, 46, 2596.

19. H. Li, J. Zhai, and X. Sun, Langmuir, 2011, 27, 4305.

20. W. L. Sun, J. L. Yao, T. M. Yao, and S. Shi, Analyst, 2013, $138,421$.

21. I. Meistermann, V. Moreno, M. J. Prieto, E. Moldrheim, E. Sletten, S. Khalid, P. M. Rodger, J. C. Peberdy, C. J. Isaac, A. Rodger, and M. J. Hannon, Proc. Natl. Acad. Sci. U. S. A., 2002, 99(8), 5069.

22. S. L. Wu, J. Dou, J. Zhang, and S. F. Zhang, J. Mater. Chem., 2012, 22, 14573.

23. Y. L. Yu, L. R. Xu, J. Chen, H. Y. Gao, S. Wang, J. Fang, and S. K. Xu, Colloid Surf., B, 2012, 95, 247.

24. W. W. Yu, L. H. Qu, W. Z. Guo, and X. G. Peng, Chem. Mater, 2003, 15, 2854.

25. J. Wang, J. G. Liang, Z. H. Sheng, and H. Y. Han, Microchim Acta, 2009, 167, 281. 